\title{
Instructional Scaffolding To Support III-Structured Problem Solving: A Review
}

\author{
Diyana Jamari, Norasykin Mohd Zaid, Zaleha Abdullah, Hasnah Mohamed, Baharuddin Aris*
}

Department of Educational Sciences, Mathematics and Creative Multimedia, Faculty of Education, UniversitiTeknologi Malaysia, 81310 UTM Johor Bahru, Johor, Malaysia

*Corresponding author: bba@utm.my

\begin{abstract}
Provision of an alternative instructional platform has encouraged students' involvement in online social collaborative learning that could potentially enhance problem-solving (PS) skill. There are many types of scaffoldings proposed by researchers to inculcate this skill; however, concern arises as a result of an illdefined problem. Besides being complex than a well-defined problem, its uniqueness originates from the integration of domains in a problem and multiple solutions that can be generated out of it. This study aims to identify the dominant type of scaffold used to guide ill-defined PS, to determine the common platform used and the education level where ill-defined PS is mostly studied. The search and review of relevant articles were done through online databases, journals and Google Scholar search engine using keywords of scaffolding problem solving, ill-structured problem, scaffolding ill-defined problem and support in PS. The findings revealed that metacognitive scaffolding (MS) is dominant in supporting ill-structured PS. MS assists in realigning the thinking of an individual to ensure proactive measures taken in the process of PS. Nevertheless, majority of the previous studies of MS were carried out in higher institutions instead of schools and within formal platform e.g., Learning Management System (LMS). Thus it is hoped that this review will give insights for educators to inculcate MS and improve PS skill in schools and through the use of new platform of social media.
\end{abstract}

Keywords: Metacognitive scaffolding; ill-structured problem solving; ill-defined problem; online learning; social media

(C) 2017 Penerbit UTM Press. All rights reserved

\subsection{INTRODUCTION}

Education transformation towards the 21st century learning emphasizes on producing students who are proficient in solving problems [1, 2]. Rote learning strategy has failed to stimulate students' analytical thinking skill and inquisitive mind [3]. Therefore, researchers emphasize the need to introduce and train students to solve ill-structured problems as they contribute to deeper meaningful learning, enable students to portray the relevance of knowledge learnt in school and facilitate knowledge transfer by contextualizing knowledge in authentic real-world situations $[4,5]$. In the future, a balance of high quality future manpower can be generated in terms of knowledge and mastery of skills. Generally, problems are classified into ill-defined and well-defined problem [6]. Previously, [5] streamlined problems according to four criteria based on the problem's structure, dynamicity, complexity and major's domain. Both well-defined and ill-defined terms were used in conjunction with some other labels that share similar criteria such as routine/non-routine, algorithm/non-algorithm including wellstructured/ill-structured. Well-structured problems can be solved straightforwardly as the solution strategy is linear and easily memorized. Exercises and drill practice will increase familiarity of this structure, and thus enables fast memory recall as the same step of solution that applies to each problem. As with ill-structured problems, they often require complex cognitive operations and deep thinking [5]. Due to the uniqueness of ill-structured problem, learners require additional support to understand and clarify conceptual or declarative knowledge learned. This type of support that facilitates students in learning is referred to as instructional scaffolding.

\subsection{INSTRUCTIONAL SCAFFOLDING}

Instructional scaffolding refers to assistance, tool or strategies that aid learners during learning [7]. It makes learning process easier for them and increases the chances to achieve the learning objectives. Eventually, this scaffold will undergo fading process, which is to be removed gradually as learners are able to master the learning content or skills targeted. Research indicates that the different uses of scaffolds in various learning situations have influenced learners' achievement and attitudes [8]. The development of teaching approaches and strategies has changed the original concept of scaffolding. The terminology More Knowledgeable Others (MKO) by Vygotsky (1978), which is synonymous with scaffolding activity, now seems to have limitations as it was previously explained as individual interaction in terms of learning assistance. With the generalization of this term, group interaction, any materials, resources, tools and learning environments that aid the learning process are indirectly to be considered as scaffolding [7, 8, 9]. This diversity has finally led to a variation in scaffolding classification, and research has indicated that a variety of scaffolds are required to accommodate learners' different 
levels of knowledge. Table 1 lists several categories of scaffolding developed and classified as guidance or learning during teaching and learning process.

Table 1 Categories of scaffolding developed as guidance for learners

\begin{tabular}{|c|c|}
\hline Authors & Scaffolding \\
\hline [10] & $\begin{array}{ll}\text { 1. } & \text { Modeling of desired behaviors } \\
\text { 2. } & \text { Offering explanations } \\
\text { 3. } & \text { Inviting students to participate } \\
\text { 4. } & \text { Verifying and clarifying student understandings } \\
\text { 5. } & \text { Inviting students to contribute clues. }\end{array}$ \\
\hline [8] & $\begin{array}{ll}\text { 1. } & \text { Hard scaffolding } \\
\text { 2. } & \text { Soft scaffolding }\end{array}$ \\
\hline [11] & $\begin{array}{ll}\text { 1. } & \text { Orientation: Communication of expectation } \\
\text { 2. } & \text { Coaching } \\
\text { 3. } & \text { Eliciting articulation } \\
\text { 4. } & \text { Task support } \\
\text { 5. } & \text { Expert regulation } \\
\text { 6. } & \text { Metacognitive scaffolding } \\
\text { 7. } & \text { Conceptual scaffolding } \\
\text { 8. } & \text { Strategic scaffolding } \\
\text { 9. } & \text { Procedural scaffolding } \\
\end{array}$ \\
\hline [12] & $\begin{array}{ll}\text { 1. } & \text { Metacognitive scaffolding } \\
\text { 2. } & \text { Conceptual scaffolding } \\
\text { 3. } & \text { Strategic scaffolding } \\
\text { 4. } & \text { Procedural scaffolding } \\
\end{array}$ \\
\hline [13] & $\begin{array}{ll}\text { 1. } & \text { Procedural Instruction } \\
\text { 2. } & \text { Procedural Coaching } \\
\text { 3. } & \text { Procedural Tool } \\
\text { 4. } & \text { Conceptual Instruction } \\
\text { 5. } & \text { Conceptual Coaching } \\
\text { 6. } & \text { Conceptual Tool } \\
\text { 7. } & \text { Metacognitive Instruction } \\
\text { 8. } & \text { Metacognitive Coaching } \\
\text { 9. } & \text { Metacognitive Tools }\end{array}$ \\
\hline
\end{tabular}

Brush and Saye [8] provide the simplest and most widely used classification [14]. Scaffolding is classified into two main types, namely hard and soft scaffolding based on its dynamic features. Soft scaffolding refers to dynamic support such as assistance given by teachers during classroom lesson. The support provided is different in each case or for each learner as it is based on learners' specific needs [8, 15]. In contrast, hard scaffolding refers to static kind of support and is often associated with teaching aids and advanced organizers, such as learning software that can be developed in advance based on typical learner difficulties [8, 15]. However, hard scaffolding does not emphasize learners' different needs and often does not undergo the fading process, which is the removal of scaffolding once the potential competency is reached.

In terms of online learning, Hannafin, Land and Oliver [12] has previously identified and introduced four types of scaffolding, namely conceptual, metacognitive, procedural, and strategic scaffolding which refers to scaffolding done by the instructors online. Conceptual scaffolding assists in defining things and often involves knowledge in domain related to PS. Metacognitive scaffolding assists in managing thinking process including planning, monitoring, and evaluating process to ensure fruitful PS activity. Planning observes how learners set objectives in learning and map their study. Monitoring allows learners to monitor what they have learned and receive feedback on their performances. Evaluation is the stage where learners can criticize each other's work and discuss with instructors on content revision. Procedural scaffolding assists individuals in making use of materials and available resources to seek solutions while strategic scaffolding, on the other hand, refers to an alternative approach that can scaffold learners during analysis, planning, strategy, and tactical decision-making processes. Strategic scaffolding assists learners in identifying the information needed, in evaluating resources, and in relating the information to their existing knowledge and experiences [12]. This is a kind of guidance that will lead learners to achieving their learning objectives by directly or indirectly assisting them, and also by suggesting approaches, strategies or pathways.

\subsection{METHODOLOGY}

This study aims to answer three objectives:

i. To gain an overview regarding the dominant type of instructional scaffolding strategies implemented to guide and support illstructured PS,

ii. $\quad$ To determine the common platform used, and

iii. To identify the level of education in which ill-defined PS is mostly studied.

In the early phase, several keywords were used to search for related relevant publications such as scaffolding problem solving, complex problem solving, scaffolding ill-structured problem, scaffolding ill-defined problem and support in problem solving through online databases, journals and Google Scholar search engine. All hits were filtered so that only research articles on scaffolding of illstructured or ill-defined PS skill published from 2000 onwards were reviewed. The articles from the conference proceeding were not selected as to avoid the redundancy, where similar articles can be found in proceedings and published journals. In the second phase, all 
filtered hits were scanned again for the inclusion criteria outlined by the researcher. The limitation of this study was due to the restricted period of article searched, as this may cause the researcher to miss out other related articles relevant to this study. After the qualitative analysis, 18 articles were found to match the criteria mentioned and the research questions. The analysis on the type of scaffolding that aid in ill-structured PS classified according to the category proposed by [8] and [12] were summarised and presented in Table 2 together with the common platform used and the level of education where ill-defined PS is mostly studied.

Table 2 Type of scaffolding applied in ill-structured problem solving

\begin{tabular}{|c|c|c|c|c|}
\hline Education Level & Setting & Platform & Scaffolding Type & Authors \\
\hline Primary School & Offline & Classroom & Conceptual \& Metacognitive & [7] \\
\hline \multirow{3}{*}{ Secondary School } & \multirow{2}{*}{ Offline } & \multirow{2}{*}{ Classroom } & Soft \& Hard & {$[8]$} \\
\hline & & & Conceptual \& Metacognitive & [9] \\
\hline & Both & Both & Soft \& Hard & [16] \\
\hline \multirow{14}{*}{ College } & \multirow{4}{*}{ Online } & \multirow{4}{*}{$\mathrm{CMC}$} & Justification /Argumentation & [17] \\
\hline & & & Justification/ Argumentation & [18] \\
\hline & & & Procedural, Metacognitive \& Strategic & [19] \\
\hline & & & Procedural \& Metacognitive & [20] \\
\hline & Both & \multirow{8}{*}{ LMS } & Cognitive \& Metacognitive & [21] \\
\hline & \multirow{7}{*}{ Online } & & Cognitive \& Metacognitive & [22] \\
\hline & & & Procedural \& Metacognitive & [23] \\
\hline & & & Metacognitive & [15] \\
\hline & & & Procedural, Metacognitive, Strategic \& Conceptual & [24] \\
\hline & & & Metacognitive, Content-specific \& Hard & [25] \\
\hline & & & Conceptual \& Metacognitive & [26] \\
\hline & & & Metacognitive & [27] \\
\hline & Online & Web 2.0 & Procedural, Metacognitive, Strategic \& Conceptual & [28] \\
\hline & Offline & Classroom & Metacognitive & {$[29]$} \\
\hline
\end{tabular}

\subsection{RESULTS AND DISCUSSION}

\section{Dominant Type off Scaffolding}

Metacognitive scaffolding (MS) appeared to be the favoured type of learning scaffolding studied in ill-structured PS as 14 out of 18 studies listed employed it in their intervention. In [7], the effects of guidance on general domain of ill-structured problem included the assistance of MS in transferring of information involved in problem solving skills, especially in terms of monitoring and evaluation of solutions besides having positive impact in mastering knowledge. The learners were found to be able to propose solutions, able to evaluate and justify for a better solution, and in addition, manage to provide alternative solutions. The findings of An [28] supported this as technologybased scaffolding and online tools, such as wikis and podcasts, not only support learners in metacognitive aspect, but also work in helping teachers to understand the learners' needs from the conceptual aspects. This in turn leads to specific conceptual scaffolding that will fulfil the specific requirement of the learners. An [28] continued the research by studying the specific role and impact of MS in the process of solving the problem of ill-structured questions through question prompts problems [25]. Their results were in line with earlier study conducted by [21], which found that MS treatment of question prompts showed significant improvement in all four process of PS, namely identifying problem, finding solution, solution implementation, and monitoring. The study by [28] was more specific as it referred to the online scaffolding classification recommended by [12], while [7] referred to the general classification of [8].

Metacognitive refers to the ability to reflect the performance of oneself. Therefore, learners learn to monitor and steer the direction of their own progress, ask questions among themselves that helps maximize effective strategies, and prevent them from continuing the approach that is not productive in generating solutions [30]. The term metacognitive scaffolding was first introduced by [12] by adapting the metacognition concept by John Flavell [30], combined with learning aid concept in conjunction with the Zone of Proximal Development (ZPD) mentioned by Lev Vygotsky [31] in his theory. Hannafin et al. [12] mentioned that this type of scaffolding helps learners identify the known information, what other information is required to solve the problem, and how to think effectively during the learning process. Metacognitive scaffolding motivates and leads learners to keeping on moving forward during problem solving. At the same time, learners undergo an active role of self-reflection to evaluate their learning process. It is actually a strategy concerning the cognitive awareness on what learners have learnt or experienced before [32], by assisting them to plan, determine their learning needs or issues and assess their learning progress [33]. Metacognitive scaffolding is expected to boost up learners' learning competence by means of a systematic approach and assisting learners to maneuver the problems confronted during learning by understanding the metacognition aspects including metacognitive knowledge, metacognitive judgement and monitoring, as well as metacognitive self-regulation and control [14].

Metacognitive skills are highly useful to measure individual competencies in thinking and learning as this skill is highly crucial for reflective judgment especially in problem-solving and decision-making [14]. Thus, metacognitive scaffolding appropriately supports metacognitive activities that aid students to concentrate and accomplish better during PS process. Furthermore, it helps teachers to identify the learners' needs from the conceptual aspect. Since learners with strong metacognitive skills are known to be a good problem solver [21, 26], a well-planned and pertinent provision of MS to support metacognition of the learners is needed in order to facilitate the learners to focus during thinking and eventually in problem solving [23, 25]. With the emergence of online learning and distance learning, [33] acknowledged seven metacognitive scaffolding mechanisms found to be use by the instructors during online instructions. These include: 
ii. Presenting the relationship between reading items, course objectives and tasks.

iii. Supporting reflective writing.

iv. $\quad$ Focusing on the process of learning.

v. Encouraging relationships among participants.

vi. Discriminating between conclusion/fact/opinion/hypothesis.

vii. Supervising text comprehension.

One common assumption associated with the student-centered, technology-enhanced learning environment is that learners should be accountable for monitoring and reflecting upon the learning process [12]. They must possess the capability to monitor thoughts and actions; they are expected to practise and implement higher order thinking skills in processing relevant information to generate products, and evaluate the efficiency and effectiveness of personal approaches during problem solving particularly ill-structured problem. Even though dealing with learners' metacognition is not an easy task however, with the presence of metacognitive scaffolding, it certainly requires learners to carry out certain tasks or activities when the learning takes place. The process of skill mastery itself may require drills and practices over a period of time. Nonetheless, this is not impossible too as earlier researchers have determined that metacognitive can be trained [21].

Besides MS, this analysis found that procedural scaffolding [19, 20, 23, 24, 28] assists individuals in making use of materials and available resources to achieve solutions [12]. Since the online platform is now commonly used for numerous learning activities, it is not surprising to discover this kind of scaffolding among the researchers' preference. Less face-to-face interaction happens with the LMS, $\mathrm{CMC}$ and social media taking over lecturing activity in a physical classroom. Online learning occurs on platform with the affordance for synchronise or asynchronies collaboration and communication. Davis [34] mentioned that procedural scaffolding can be one of the aids and efforts that are considered to be a worthwhile implementation in these types of learning environment. Her definition of procedural scaffolding revolves around addressing how learners will interact with the instructors, other learners, and the contents delivered online. Among the examples of procedural scaffold according to [34] include personal homepages, periodic emails among instructors and learners, and extensive feedback from the instructors and peers. All these contribute to the creation of a conducive and personal learning environment, and at the same time encourage learners to maintain an effective and interactive learning community online that motivate learners to stay connected, engaged, and successful.

In online learning, this type of scaffolding helps learners to understand the use of platform chosen to deliver the learning contents, such as step-by-step content-related instruction or demo videos to ensure a smooth implementation of designed learning plan, including how to navigate the online course environment and engage in the learning activities [35]. Three types of procedural scaffold that help learners persist include expectation, orientation, and resources scaffold [35]. Orientation includes basic internet skills, ways of communicating in order to give and receive feedbacks, and the rules of netiquette. Expectation refers to the need to meet an aim which has been declared as an example, the important dates, duration, and the course outcome to be achieved. Resource scaffold helps to outline the use of templates, advance organizers, or teaching aids provided to support and develop critical thinking and problem solving. As it is more towards technicality in nature, studies related to it commonly require leaners' proficiency to handle various tools so that it can be maximally utilized in the intervention or to produce material as the finding of interventions.

An and Cao [25] implemented content specific scaffolding in their study which actually refers to conceptual scaffolding. Besides procedural scaffolding, content specific scaffolding also showed to be among the researcher's preference. However in our opinion, since content scaffolding content is the ultimate goal of learning assistance given to students either with or without the teacher's presence or other instructional materials. Hence, it will not be discussed further in this paper.Other types of least studied scaffolding do not suggest that these other scaffoldings are irrelevant in PS. It is well-understood that the choice of scaffolding used during the intervention was based on its research objectives.

\section{Common Platform Used In Ill-Structured PS Research}

Two studies were found to have been conducted in a mixed mode [16, 21]. Four studies were done totally offline, while the remaining twelve studies were done online. This is in line with the technological developments that renders the ability of the learning process to be performed anywhere without any constraints of location and time.

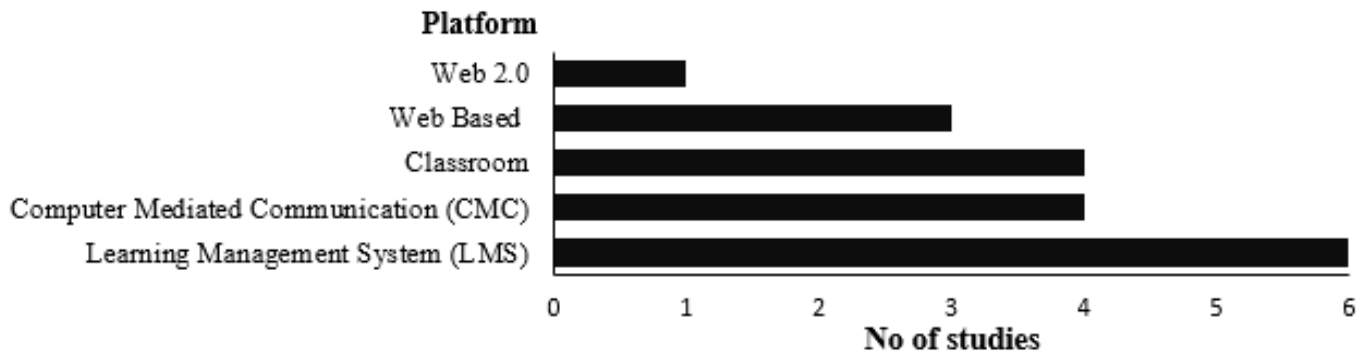

Figure 1 Platform used in Ill-Defined PS research.

Based on Figure 1, studies done offline used a variety of software or hypermedia applications [7, 8, 9,], lab sessions [21] and face-to-face PS discussion groups [29]. Out of 14 studies done online, six were carried out on Learning Management System (LMS) platform, 4 on Computer Mediated Communication (CMC), three studies on web-based learning environment, while one study specifically focused on the use of Web 2.0 tools.

$\mathrm{CMC}$ is a concise term that applies to all methods in terms of communication via a computer. It can be synchronous where all participants are online simultaneously or time constraints asynchronous communication modes such as emails and instant messaging (IM). 
The key features of CMC include conversation record ability, formal communication, and user identity anonymity depending on the software type. On the other hand, LMS, such as Moodle and Blackboard which also known as e-learning, is a software application for managing courses over the Internet [36]. Despite their differences, online collaboration features of CMC and discussion forum in LMS are able to accommodate the interaction process and discussion activities in line with the 21 st century education trend, as teaching and learning direction now focuses on student-centred approach [36]. The integration of new technologies in learning has brought significant changes in the learning process as a whole. Since blended learning is now prominent in the tertiary education, LMS and CMC have become a common platform for disseminating information, mediating online discussion, and sharing material purposes among college students, thus making them as a good option for PS research. Positive response received, such as time saver due to fast response, has captured learners' interest to continue using these platforms for learning process even after class. The same phenomenon goes to web-based learning environment applied by [20, 22, 29], while some other researchers use this platform in blended learning setting [16, 21]. Collaboration among peers will encourage learners to share ideas, voice out their opinions, and justify their reasons [14, 37]. Thus, the application of online discussion activities helps to improve problem-solving skills as well as critical thinking in an informal learning environment. However, it still requires planning to avoid deviation from the intended purpose. Student-centred online learning concept is known to shape learners to become more responsible, aid in fostering communication skill and proactive attitude, groom learners to become independent thinkers as well as help educate them regarding the ethics and integrity in the process of learning [38]. Whether face-to-face or via online learning, the same process will occur. Hence, consideration should be given to exploring the opportunities and possibilities of the Internet to promote learning including PS skill.

\section{Education Level Where Ill-Structured PS Is Mostly Studied}

Scaffolding studies related to ill-structured PS are predominantly conducted in higher education compared to school level, where less amount of studies have been done involving students in school level. There are only three studies involving secondary students [8, 9, 16], while one study was conducted in primary school [7] (Figure 2).

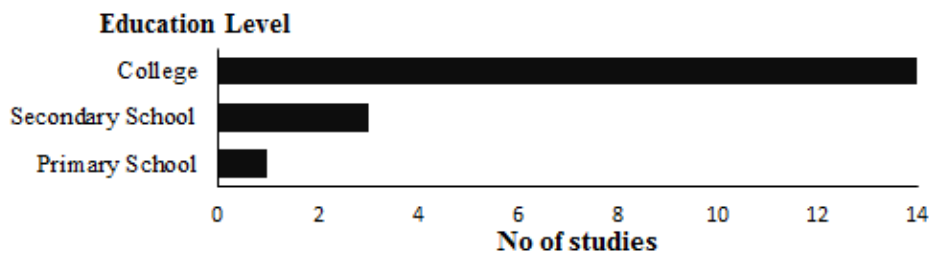

Figure 2 Education level where Ill-Define PS mostly studied.

The growth of communication technologies in higher learning institutions has resulted in the incorporation of technology into their curriculum. The emergence of blended learning implementations indirectly introduces the use of an online platform for information, communication and disseminating learning materials. This has increased the demand of LMS usage that is beneficial to ensure continuous learning and to complement limited face-to-face learning instruction. The studies involving school students [7 8 9, 16] were mostly conducted in classroom setting, even though the pattern of PS studies has shifted towards open and online learning following the progress and development of technology in education. This condition may be due to the limited number of computers and Internet provision compared to those provided in tertiary education, as well as due to the rigid class schedule and syllabus, including the banning of handheld gadgets in most schools. Teacher-centred learning approach and well-structured problem-solving that have limited relevance and transferability to solving problems that are situated in everyday contexts are being practised in schools [28, 39]. The content syllabus at school level focuses more on a well-structured form of PS. These forms of questions are usually specific-domain and are rarely those that require the implementation of higher-order thinking skills, as it can be solved with a linear approach based on specific answers or goals. This may also contribute to the reason why less ill-defined PS studies are conducted in school level.

\subsection{RECOMMENDATION FOR FUTURE RESEARCH}

In [28], the author highlighted the use of Web 2.0 tools. However, it does not cover all tools including the social media. In terms of communication and interaction function, social media too have the potential to be an alternative promising platform. The rise of mobile technology, Wi-Fi-friendly places, and the popularity of social media that is in trend within the modern community nowadays has attracted many researchers to study the possibilities of social media to be used as learning platform [40, 41]. Although LMS is widely accepted by learners, its lack of social connectivity tools and personal profile spaces has been outshone by social media such as Facebook. Learners demand learning through multilateral interaction, and they prefer autonomy in terms of materials and sources selection and connectivity in learning [42]. Overall, learners' participation increased, and more additional learning material exchanges occurred and positive perception were derived in the study. As most learners own social media account, access to group page becomes easier compared to LMS, which requires student to navigate through the university website to $\log$ on to the system. A survey on social media involving adolescents aged 16-19 years found that Facebook is listed among the most frequently used by learners [43, 44]. Facebook has been named as one of the 21 st century tools that holds the potential to bring transformation in student-centred teaching and learning, as it meets the criteria of learners' ownership in learning [41]. Its less formal features encourage learners to express themselves, while reflective elements and feedback mechanism promote the context-based interaction that emphasizes social harmony communication between learners and teachers [45]. In addition, comfortable personal environment will contribute and support lifelong learning [46].

Munoz and Towner [47] disagreed and pointed out that the informal feature is actually the reason why some educators refuse to use Facebook. This opinion is in contrary to the idea of which stated that the Y [48] and Z [49] generations learners, who are also known as digital native's learners, should be allowed to apply learning through social media as it has become part of their routine activities [50]. 
Despite having handheld gadget banned from school in some countries, it is believed that digital natives' learners will still be using this media outside school hours. It is because being active on social media is synonymous with the technology trends now. Research documented the positive impact of learning through social media, particularly Facebook, in enhancing learners' motivation and engagement [51], fostering positive attitude [52], improving writing [50], and helping in developing interpersonal skills and critical thinking [53]. These findings enhanced the positive possibility of using this media as a tool to assist pedagogy [50]. Along this awareness, schools practice in Canada and New Zealand has begun to allow learners to bring their own devices such as smartphones or tablets to school through the implementation of Bring Your Own Device (BYOD) program [54]. In line with the development in education, BYOD is regarded as a model of technology for the 21st century learning as "Mobile + Social Media = Self Learning", which is able to foster learning independently by collaborating access to any media and their preferred devices. The integration of social networks into existing learning practices creates an opportunity and practical medium to improve the process of delivering a robust learning [42].

\subsection{CONCLUSION}

It has become a trend among the researchers to integrate MS in an ill-structured PS due to the positive outcome documented previously. MS supports learners by assisting individual learning management and by guiding appropriate thinking during learning. Gaining PS skill competency requires time; however, it can be developed by learning and practicing. Hence, this skill needs to be nurtured as early as during school years. Despite extensive research regarding MS, less information was available that explicitly discusses how MS affects the PS skills in terms of complex ill-structured PS in the vicinity of online learning, specifically in the social media platform which is less known for learning purpose. Therefore, there is a call for more thorough research on MS to improve PS skill in terms of ill-structured problem especially with the emerging use of social media such as Facebook. Although Facebook was originally design for social purpose, it has the potential to be manipulated for effective learning under a precise planning. Most of the studies were focused on learners in higher education and online settings, and they were conducted mainly outside Malaysia. In the Malaysian context, local study should be conducted to explore the impact of MS in developing PS skill especially involving ill-structured problems.

\section{References}

An, Y.J. (2010). Scaffolding Wiki-Based, Ill-Structured Problem Solving in an Online Environment. MERLOT Journal of Online Learning and Teaching, 6(4), 723734 .

An, Y.J. and Cao, L. (2014). Examining the Effects of Metacognitive Scaffolding on Students' Design Problem Solving and Metacognitive Skills in an Online Environment. Journal of Online Learning and Teaching, 10(4), 552-568.

Bixler, B.A. and Land, S.M. (2010). Supporting College Students' Ill-Structured Problem Solving in a Web-Based Learning Environment. Journal of Educational Technology Systems, 39(1), 3-15.

Brickell, G. and Herrington, J. (2006). Scaffolding Learners in Authentic, Problem Based E-Learning Environments: The Geography Challenge. Australasian Journal of Educational Technology, 22(4), 531-547.

Brush, T. and Saye, J.W. (2002). Scaffolding Critical Reasoning About History and Social Issues in Multimedia-Supported Learning Environments. Educational Technology Research and Development, 50(3), 77-96.

Bulu, S.T. and Pedersen, S. (2010). Scaffolding Middle School Students' Content Knowledge and Ill-Structured Problem Solving in a Problem-Based Hypermedia Learning Environment. Educational Technology Research and Development, 58(5), 507-529.

Byun, H., Lee, J. and Cerreto, F.A. (2014). Relative Effects of Three Questioning Strategies in Ill-Structured, Small Group Problem Solving. Instructional Science, $42(2), 229-250$.

Chen, C.H. (2014). Nurturing Students' Problem-Solving Skills and Engagement in Computer-Mediated Communications (CMC). Journal of Interactive Learning Research, 25(3), 309-325.

Chen, C.H. and Bradshaw, A.C. (2007). The Effect of Web-Based Question Prompts on scaffolding knowledge Integration and Ill-Structured Problem Solving. Journal of Research on Technology in Education, 39(4), 359-375.

Cho, K.L. and Jonassen, D.H. (2002). The Effects of Argumentation Scaffolds on Argumentation and Problem Solving. Educational Technology Research and Development, 50(3), 5-22.

Davis, M. (2006). Using Procedural Scaffolding to Support Online Learning Experiences. In Proceedings of IEEE International Professional Communication Conference.

Ellis, R.K. (2009). Field Guide to Learning Management Systems. ASTD Learning Circuits.

Evren, A., Bati, K. and Yilmaz, S. (2012). The Effect of Using V-diagrams in Science and Technology laboratory Teaching on Preservice teachers' Critical Thinking Dispositions. Procedia-Social and Behavioral Sciences, 46, 2267-2272.

Farreira, D.J. and Dos Santos, G.L. (2009). Scaffolding Online Discourse in Collaborative Ill-Structured Problem-Solving for Innovation. Informatics in Education, $8(2), 173-190$.

Flavell, J.H. (1976). The Nature of Intelligence. New Jersey: Lawrence Erlbaum Associates.

Ge, X. (2010). Scaffold Ill-Structured Problem Solving Processes Through Fostering Self-Regulation-A Web-Based Cognitive Support System. In 2010 Cognitive and Metacognitive Educational Systems, AAAI Fall Symposium.

Ge, X. and Land, S.M. (2003). Scaffolding Students' Problem-Solving Processes in an Ill-Structured Task Using Question Prompts and Peer Interactions. Educational Technology Research and Development, 51(1), 21-38.

Ge, X., Chen, C.H. and Davis, K.A. (2005). Scaffolding Novice Instructional Designers' Problem-Solving Processes Using Question Prompts in a Web-Based Learning Environment. Journal of Educational Computing Research, 33(2), 219-248.

Gotwals, A.W. and Songer, N.B. (2013). Using Assessment to Gather Validity Evidence for a Learning Progression on Evidence-Based Explanations with Core Ecological Content. Journal of Research in Science Teaching, 40, 597-626.

Hannafin, M., Land, S. and Oliver, K. (1999). Instructional Design Theories and Models: A New Paradigm of Instructional Theory. New Jersey: Lawrence Erlbaum Associates.

Hardin, L.E. (2003). Problem-solving Concepts and Theories. Journal of Veterinary Medical Education, 30(3), 226-229.

Hew, K. and Knapczyk, D. (2007). Analysis of Ill-Structured Problem Solving, Mentoring Functions, and Perceptions of Practicum Teachers and Mentors Toward Online Mentoring in a Field-Based Practicum. Instructional Science, 35(1), 1-40.

Hogan, K., \& Pressley, M. (Eds.). (1997). Scaffolding Student Learning: Instructional Approaches and Issues. Cambridge, MA: Brookline.

Hutchinson, M. (2015). Netflix, Social Media Trumps Cable for Toronto Students. The Ryersonian: Ryerson School of Journalism.

Johari, S., Nur Hasniza, I. and Dalim, S.F. (2014). Problem Solving: Algorithms and Conceptual and Open-Ended Problems in Chemistry. Procedia-Social and Behavioral Sciences, 116, 4955-4963. 
Jonassen, D.H. (1997). Instructional Design Models for Well-Structured and Ill-Structured Problem-Solving Learning Outcomes. Educational Technology Research and Development, 45(1), 65-94.

Kent, M. (2013). Changing the Conversation: Facebook as a Venue for Online Class Discussion in Higher Education. Journal of Online Learning and Teaching, 9(4), $546-565$.

Kirschner, P.A. and Karpinski, A.C. (2010). Facebook® and Academic Performance. Computers in Human Behavior, 26(6), 1237-1245.

Koh, K.H., Tan, C. and Ng, P.T. (2012). Creating Thinking Schools Through Authentic Assessment: The Case in Singapore. Educational Assessment, Evaluation and Accountability, 24(2), 135-149.

Lampe, C., Ellison, N. and Steinfeld, C. (2008). Changes in Use and Perception of Facebook. In Proceedings of the ACM Conference on Computer Supported Cooperative Work, 721-730.

Lee, M.J.W. \& Delgarno, B. (2012). Dimension of Scaffolding in Technology-Mediated Discovery Learning Environments. In van Aalst, J., Thompson, K., Jacobson, M. J. \& Reimann, P. (Eds.). The Future of Learning. In Proceedings of the 2012 International Conerence of the Learning Sciences. 2-6 July. Sydney, Australia: 2, 227-231.

Mason, R. (2006). Learning Technologies for Adult Continuing Education. Studies in Continuing Education, 28(2), 121-133.

Mazman, S.G. and Usluel, Y.K. (2010). Modeling Educational Usage of Facebook. Computers \& Education, 55(2), $444-453$.

McLoughlin, C. (2004). Achieving Excellence In Teaching Through Scaffolding Learner Competence. In Proceedings of the 13th Annual Teaching Learning Forum. Perth: Murdoch University. 9-10 February 2004

Miron, E. and Ravid, G. (2015). Facebook Groups as an Academic Teaching Aid: Case Study and Recommendations for Educators. Educational Technology \& Society, 18(4), 371-384.

Munoz, C. and Towner, T. (2009). Opening Facebook: How to use Facebook in the College Classroom. In Proceedings of Society for Information Technology \& Teacher Education International Conference, AACE, 2623-2627.

Ng, C.S.L., Cheung, W.S. and Hew, K.F. (2010). Solving Ill-Structured Problems in Asynchronous Online Discussions: Built-In Scaffolds vs. No Scaffolds. Interactive Learning Environments, 18(2), 115-134.

Nurul Farhana, J., \& Zaidatun, T. (2015). Metacognitive Scaffolding to Support Students in Learning Authoring System Subject. In Proceedings of Learning and Teaching in Computing and Engineering (LaTiCE 2015) International Conference. 9-12 April. Taipei, Taiwan: IEEE, 87-90.

Oh, S. and Jonassen, D.H. (2007). Scaffolding Online Argumentation During Problem Solving. Journal of Computer Assisted Learning, 23(2), 95-110.

Petrović, N., Petrović, D., Jeremić, V., Milenković, N., \& Cirović, M. (2012). Possible Educational Use of Facebook in Higher Environmental Education. In Proceedings of the International Conference on Information Communication Technologies in Education, ICICTE2012.

Prensky, M. (2005). Listen to the Natives. Educational Leadership, 63(4), 8-13.

Rafiza, A.R. and Maryam, A.R. (2013). Pembinaan Media Pengajaran Berasaskan Multimedia Di Kalangan Guru ICTL. Jurnal Kurikulum \& Pengajaran Asia Pasifik, 1(2), 20-31.

Reingold, R., Rimor, R., \& Kalay, A. (2008). Instructor's Scaffolding in Support of Student's Metacognition Through a Teacher Education Online Course: A Case Study. Journal of Interactive Online Learning, 7(2), 139-151.

Robinson, J.H. (2015). The Mind in Making.. Worcestershire: Read Books Ltd.

Saikaew, K., Krutkam, W., Pattaramanon, R., Leelathakul, N., Chaipha, K. and Chaosakul, A. (2011). Using Facebook as a Supplementary Tool for Teaching and Learning. In Proceedings of International Conference on eLearning Futures.

Shahizah, S. and Zaidatun, T. (2014). Promoting Critical Thinking Through Asynchronous Online Discussion Forum: The Theoretical Framework. In Proceedings of the 2014 International Education Postgraduates Conference, IEPS2014.

Shatto, B., \& Erwin, K. (2016). Moving on From Millennials: Preparing for Generation Z. The Journal of Continuing Education in Nursing, 47(6), 253-254.

Song, Y. (2014). Bring Your Own Device (BYOD) for Seamless Science Inquiry in a Primary School. Computers \& Education, 74, 50-60.

Stavredes, T.M. (2011). Effective Online Teaching: Foundations and Strategies for Student Success. San Francisco: JosseyBass.

Wang, R. (2015). LS Vygotsky and Education. British Journal of Educational Studies, 63(1), 112-114.

Way, J., \& Rowe, L. (2008). The Role of Scaffolding in the Design of Multimedia Learning Object. In Proceedings of 11th International Congress on Mathematical Education. 6 July - 13 July 13 . Mexico.

West, A., Lewis, J. and Currie, P. (2009). Students' Facebook 'Friends': Public and Private Spheres. Journal of Youth Studies, $12(6), 615-627$.

Xie, K. and Bradshaw, A.C. (2008). Using Question Prompts to Support Ill-Structured Problem Solving in Online Peer Collaborations. International Journal of Technology in Teaching and Learning, 4(2), 148-165.

Zydney, J.M. (2008). Cognitive Tools For Scaffolding Students Defining An Ill-Structured Problem. Journal of Educational Computing Research, 38(4), 353-385. 